Article

\title{
Production of a Polyclonal Antibody against the Recombinant Coat Protein of the Sugarcane Mosaic Virus and Its Application in the Immunodiagnostic of Sugarcane
}

\author{
Nurmalasari Darsono 1,2 (1), Novita Niswatun Azizah ${ }^{3}$, Kiky Mey Putranty ${ }^{3}$, Natalia Tri Astuti ${ }^{1}$, \\ Hardian Susilo Addy ${ }^{4,5}$ (D), Win Darmanto ${ }^{2}$ and Bambang Sugiharto ${ }^{3,5, *}$ \\ 1 Laboratory of Biotechnology, PT. Perkebunan Nusantara XI, Jl. Merak No. 1, Surabaya 60175, Indonesia; \\ nurmalasari.darsono@gmail.com (N.D.); natalia_tria@yahoo.co.id (N.T.A.) \\ 2 Department of Biology, Faculty of Science and Technology, Airlangga University, Jl. Airlangga No. 4-6, \\ Gubeng, Kota Surabaya, East Java 60115, Indonesia; win-d@fst.unair.ac.id \\ 3 Department of Biology, Faculty of Mathematic and Natural Sciences, University of Jember, Jl. Kalimantan \\ No. 37, Kampus Tegalboto, Jember 68121, Indonesia; novita.niswatunazizah@gmail.com (N.N.A); \\ kikymey@gmail.com (K.M.P.) \\ 4 Faculty of Agriculture, University of Jember, Jl. Kalimantan No. 37, Kampus Tegalboto, Jember 68121, \\ Indonesia; hsaddy.faperta@unej.ac.id \\ 5 Center for Development of Advanced Science and Technology, University of Jember, Jl. Kalimantan No. 37, \\ Kampus Tegalboto, Jember 68121, Indonesia \\ * Correspondence: sugiharto.fmipa@unej.ac.id; Tel.: +62-331-321825
}

Received: 3 May 2018; Accepted: 11 June 2018; Published: 13 June 2018

\begin{abstract}
Sugarcane mosaic virus (SCMV) is a mosaic disease that has spread over sugarcane plantations in Indonesia. The important step to overcome the disease is to detect the pathogen as early as possible. Detection of the pathogen can be achieved using the immunodiagnostic method by employing a specific antibody against the viral coat protein. The objective of this research was to produce a polyclonal antibody using the recombinant coat protein of SCMV, and to test its sensitivity for detection of SCMV in the symptomatic plant. The gene encoding of the coat protein was cloned using the RT-PCR Kit and total RNA isolated from symptomatic sugarcane leaves cultivar PS-881. Nucleotide sequences analysis of the cloned cDNA indicated that the cDNA contained 998 nucleotides and named SCMVCp-cDNA. The cDNA was then inserted into a His-tag expression plasmid of pET28a and overexpressed in Escherichia coli BL21 (DE3) to produce a recombinant protein. The recombinant fused protein $S C M V C p$ was strongly expressed in an insoluble fraction, with a molecular size of around $44 \mathrm{kDa}$, without the addition of an IPTG inducer. Purification of the recombinant protein using an affinity Ni-NTA resin, followed by SDS-PAGE separation, resulted in a high purity of the protein and used as an antigen to raise the polyclonal antibody in a rabbit. The sensitivity of the antiserum determined by western blot analysis showed that the antiserum was able to detect the recombinant protein at a concentration of $10 \mathrm{ng}$. The western blot analysis also detected a clear single band of $36.7 \mathrm{kDa}$ of the SCMV coat protein in symptomatic sugarcane leaves and not in healthy leaves. Interestingly, when the sample proteins were prepared using low-speed centrifugation, the corresponding coat protein was detected in a soluble fraction by western blot analysis. Thus, the antiserum was successfully used for indirect-ELISA analysis using the soluble protein fraction. The results provide an easy method to detect and diagnose SCMV infection using the immunodiagnostic.
\end{abstract}

Keywords: sugarcane mosaic virus; polyclonal antibody; coat protein; immunodiagnostic; sugarcane 


\section{Introduction}

Sugarcane is a major crop cultivated in tropical and subtropical fields for sugar production. sugarcane mosaic virus (SCMV) is one of the main pathogens that substantially affect sugarcane productivity. Recently, it has been reported that this pathogen has spread in East Java, Indonesia [1], with an incidence rate of $78 \%$ on the sugarcane-cultivated area, and reduced the sugar production by $20 \%[2,3]$. The infected sugarcane plant shows symptoms such as a yellowish, chlorotic leaf area, which could be accompanied by varying degrees of necrosis. The chlorotic areas are mostly observed in young rapidly growing leaves and are particularly distinct in the basal portion of the leaves [4]. However, this chlorotic symptom can be the result of a failure in chlorophyll development, due to a virus infection, or a lack of an essential mineral nutrient. Furthermore, the mosaic symptoms caused by sugarcane viruses-such as sugarcane streak mosaic virus (SCSMV), sugarcane mosaic virus (SCMV), and sorghum mosaic virus (SrMV) — are difficult to distinguish by morphological observation of the symptoms [5]. The symptoms are also unstable, since symptoms are influenced by the time of infection, environment, and cultivar [6]. Thus, the identification of the causal agent of mosaic diseases is an important step in determining the appropriate control management.

Sugarcane mosaic virus belongs to the Potyviridae family, genus Potyvirus, found worldwide in over 70 countries [7], and infects some host plants—such as maize, sorghum, and several Poaceae—and is transmitted by aphids [8]. The virion is comprised of flexuous rods, about $750 \mathrm{~nm}$ in length, and has a genome of positive-sense RNA, approximately $10 \mathrm{~kb}$ long [7]. The complete genome sequences of SCMV isolated from several geographic regions have been published in the NCBI GenBank database, such isolates from Argentina (JX237862.1); Australia (AJ278405); China (AF494510.1; JN021933.1); Iran (KT895081.1); and Mexico (GU474635.1). The SCMV genome contains a single long open reading frame (ORF), which encodes a polyprotein that is post-translationally processed into the individual gene products by viral proteases, and the coat protein is encoded at the $3^{\prime}$-end terminus [9]. This coat protein has been studied intensively and highly conserved among SCMV isolates, thus facilitating detection of the virus by serological methods [10].

Several immunodiagnostic methods, as well as molecular methods, have been widely used to detect plant viruses. Traditionally, a polyclonal antibody against a purified virion from infected plant material was developed for immunodiagnostics [11]. However, the traditional preparation of a polyclonal antibody has its limitations, such as the purity of the virion and low viral titer in the infected plant tissue. This procedure is lengthy, requiring virus propagation in a suitable host, followed by virion purification [12]. To overcome this problem, the serological method using a polyclonal antibody against a recombinant coat protein, was commonly used in immunodiagnostics [11]. Several studies have reported on the production of polyclonal antibodies against recombinant proteins, such as the antibodies against coat protein of Pelargonium zonate spot virus [13], cucumber mosaic virus [14], or alfalfa mosaic virus [15].

The recombinant viral proteins that are expressed in bacterial cells have great potential as a source of antigen to produce a specific antibody. The bacterial expression system is simple, fast, and inexpensive for producing a large amount of purified proteins as antigens to produce antibodies [16]. In addition, a fusion tag added to the protein sequence and expressed in Escherichia coli, improves protein expression, solubility, and stability, and facilitates a faster purification procedure [17]. The combination of the bacterial expression system and the fusion tag protein purification has been routinely used in protein production and purification for the development of antibody [18].

In this study, we have developed a polyclonal antibody against a recombinant coat protein of the SCMV and successfully tested its sensitivity for detection of SCMV infection in sugarcane by western blot and enzyme-linked immunosorbent assay (ELISA). 


\section{Materials and Methods}

\subsection{Cloning and Sequencing cDNA of SCMV Coat Protein}

Field grown sugarcane cultivar PS-881 (4-5 months) with mosaic disease symptoms was used as the virus source. The yellowing and chlorosis symptom leaves were harvested and used for total RNA isolation using the guanidinium thiocyanate method, as described by Sambrook et al. [19]. The published CP gene sequences were used for designing the primer F1; 5'-GTTTYCACCAAGCTGGAACAGTC-3' and R1; 5'-AGCTGTGTGTCTCTCTGTATTCTCT-3' . First-strand cDNA was synthesized using a template from total RNA, with oligo dT primer and reverse transcriptase (Roche, Mannheim, Germany). Targeted coat protein cDNA was amplified using a pair of primers F1 and R1. The PCR reaction consisted of one cycle pre-denaturation at $94{ }^{\circ} \mathrm{C}$ for $5 \mathrm{~min}$, 30 cycles at $94{ }^{\circ} \mathrm{C}$ denaturation for $30 \mathrm{~s}, 56^{\circ} \mathrm{C}$ for $30 \mathrm{~s}, 68^{\circ} \mathrm{C}$ extension for $60 \mathrm{~s}$, and the final extension step at $68^{\circ} \mathrm{C}$ for $5 \mathrm{~min}$. The amplified cDNA was visualized using $1 \%$ agarose gel electrophoresis and purified using a gel extraction kit (Macherey-Nagel, Duren, Germany) according to the manufacturer's instruction. The purified cDNA fragment was ligated into a pJET1.2 vector (ThermoFisher Scientific, Waltham, MA, USA) and transformed into the E. coli strain XL10-Gold. The transformants were screened by colony PCR using F1, R1 set of primers.

The nucleotides sequence of the cDNA was determined bi-directionally, and the resulting sequence was analyzed using software Genetyx Ver.8 for Windows. The deduced amino acids sequences were compared with the GenBank NCBI database using BLASTp. The corresponding cDNA was named $S C M V C p$ and used for the production of the recombinant protein.

\subsection{Plasmid Construction for Production of the Recombinant Protein}

To produce the recombinant protein, the $S C M V C p$ was amplified using PCR with specific primers F2: 5'-GCGGATCCGTCGATGCAGGTG-3' and R2: 5'-GTGCTCGAGCAGAGAGAGTGCAT-3' to produce a $924 \mathrm{bp}$ DNA fragment, which encodes a recombinant protein (308 amino acids) starting with the DAG amino acids sequence. The DAG amino acids sequence was identified as the motif for SCMV transmission by aphid [20]. The amplified cDNA was then digested with BamHI and XhoI restriction enzymes and ligated into a pET28a expression vector (Invitrogen, Carlsbad, CA, USA). The vector contains a fusion hexa-histidine (6-His) tag at the $\mathrm{N}$ terminal for purification by affinity chromatography. The pET28a construct was subsequently transformed into E. coli XL10-Gold. The positive transformant colonies were selected by the PCR method using a set of primers for T7 promoter (5'-TAATACGACTCACTATAGGG-3') and T7 terminator (5'-GCTAGTTATTGCTCAGCGGG-3'). Recombinant plasmids were isolated from the transformant using a Plasmid Miniprep Kit (Tiangen Co., Beijing, China) and the orientation of cDNA insertion was confirmed by restriction enzymes digestion and nucleotide sequence determination. The expression plasmid vector was transformed into E. coli BL21, and the selected transformant was used for the production of the recombinant SCMVCp fusion protein.

\subsection{Production and Purification of the Recombinant SCMVCp Fusion Protein}

To analyze expression of the recombinant SCMVCp fusion protein, the E. coli BL21 transformant carrying pET28-SCMVC $p$ construct was cultured in $0.1 \mathrm{~L}$ of LB (Luria-Bertani) medium containing $50 \mathrm{ppm}$ kanamycin at $37^{\circ} \mathrm{C}$ overnight on a shaking incubator (150 rpm). The expression of the recombinant SCMVCp fusion protein was induced by addition of IPTG at 0, 0.1, 0.3, 0.5, $1.0 \mathrm{mM}$. The bacterial cells were harvested by centrifugation at $6000 \mathrm{rpm} 4{ }^{\circ} \mathrm{C}$ for $10 \mathrm{~min}$, and the pellets were suspended in an extraction buffer containing $50 \mathrm{mM} \mathrm{NaH} \mathrm{PO}_{4}$ and $300 \mathrm{mM} \mathrm{NaCl}(\mathrm{pH}$ 8). The recombinant protein was extracted by sonication and a soluble protein fraction was separated by centrifugation at $12,000 \mathrm{rpm} 4{ }^{\circ} \mathrm{C}$ for $10 \mathrm{~min}$. The proteins in total extract (before centrifugation), soluble fraction (supernatant), and insoluble fraction (pellet) were separated by SDS-PAGE (sodium 
dodecyl sulfate polyacrylamide gel electrophoresis) and then visualized by Coomassie Brilliant Blue (CBB) staining.

The production of the recombinant SCMVCp fusion protein was conducted by culturing the E. coli BL21 transformant in $5 \mathrm{~L}$ of LB medium containing $50 \mathrm{ppm}$ kanamycin at $37^{\circ} \mathrm{C}$ overnight. The bacterial cells were harvested by centrifugation and the pellet was used for protein extraction and purification. The purification of the recombinant fusion protein was conducted under denaturing condition, as the recombinant SCMVCp fusion protein was expressed in an insoluble fraction. The harvested bacterial cell was disrupted in the extraction buffer with sonication and the supernatant was separated by centrifugation at $12,000 \mathrm{rpm} 4{ }^{\circ} \mathrm{C}$ for $10 \mathrm{~min}$. The pellet cell debris was washed once with the extraction buffer, and the insoluble proteins fraction was resuspended in the solubilization buffer containing $50 \mathrm{mM} \mathrm{NaH} 2 \mathrm{PO}_{4}, 300 \mathrm{mM} \mathrm{NaCl}, 8 \mathrm{M}$ Urea (pH 8). The recombinant protein was then solubilized by incubation at room temperature with gentle shaking and then separated by centrifugation at 12,000 rpm for $20 \mathrm{~min}$. The recombinant His-tag fusion protein was purified by affinity column chromatography containing Ni-NTA resin equilibrated with the solubilized buffer according to the manufacturer's instructions (Macherey-Nagel). Unbound proteins were washed with $50 \mathrm{mM} \mathrm{NaH}_{2} \mathrm{PO}_{4}, 300 \mathrm{mM} \mathrm{NaCl}$, $8 \mathrm{M}$ Urea ( $\mathrm{pH}$ 8) containing $20 \mathrm{mM}$ imidazole, and the bounded-protein was eluted from the resin with $50 \mathrm{mM} \mathrm{NaH}_{2} \mathrm{PO}_{4}, 300 \mathrm{mM} \mathrm{NaCl}, 8 \mathrm{M}$ Urea (pH 8) containing $250 \mathrm{mM}$ imidazole.

A further purification step was conducted by separation the eluted protein with SDS-PAGE and the targeted protein band was excised and recovered from the gels by electroelution (Bio-Rad, Hercules, CA, USA). The recovered protein was dialyzed against a phosphate buffer saline (PBS) overnight at $4{ }^{\circ} \mathrm{C}$ to remove SDS from the protein mixture. After evaluating the purity with SDS-PAGE and measuring the protein concentration with the Bradford reagent (Biorad), the recombinant protein was used as an antigen for the development of a polyclonal antibody.

\subsection{Production of a Polyclonal Antibody and Estimation of the Antibody Development}

Two female New Zealand White rabbits (two months' age) were immunized subcutaneously with $500 \mu \mathrm{g}$ of purified recombinant SCMVCp fusion protein emulsified with $500 \mu \mathrm{L}$ of Freund's complete adjuvant at a ratio of 1:1 $(v / v)$. Two weeks after the first immunization, the rabbits were boosted by five additional subcutaneous injections with $100 \mu \mathrm{g}$ of the purified protein mixed with $500 \mu \mathrm{L}$ of Freund's incomplete adjuvant per injection at a ratio of 1:1 every week. The rabbits were bled five times before and after injections to collect the antiserum, which were designated as pre-immune (before immunization) or S1 (after first boosted injection) to S5 (after fifth boosted injection) antiserum and then stored at $-20^{\circ} \mathrm{C}$. The raised antiserum was monitored by Ouchterlony double diffusion analysis.

\subsection{Western Blot Analysis}

The polyclonal antiserums against the recombinant coat protein were tested by western blot and ELISA to evaluate their sensitivity and specificity. The purified SCMVCp protein, and either crude extracts of healthy or symptomatic sugarcane leaves, were used as test materials. To determine the sensitivity of the antiserum, a serial dilution of the purified SCMVCp protein was separated by SDS-PAGE. The separated proteins were electroblotted onto an Immobilon-P transfer membrane (Millipore) using semi-dry transblotter (Biorad) at a constant current of $250 \mathrm{~mA}$ for $60 \mathrm{~min}$ at room temperature. The membrane was removed from the transblotter and washed with TBS (Tris Buffer Saline) three times. After being blocked with a TBS solution containing $0.5 \%$ skim milk, the membrane was incubated with antiserum against the SCMVCp protein diluted in TBS containing $0.5 \%$ skim milk (1:3000) for overnight at room temperature with gentle agitation. The membrane was further washed three times in TBS, followed by incubation with the secondary antibody, goat anti-rabbit IgG alkaline phosphatase (AP)-conjugate (Biorad), at 1:3000 dilutions for $60 \mathrm{~min}$ at room temperature. The expected protein band was visualized by incubation in BCIP/NBT substrate (5-bromo-4-chloro 3-indolyl-phosphate/nitro blue tetrazolium) (Biorad). 
Crude leaf extracts were prepared by grinding $2 \mathrm{~g}$ of the healthy and symptomatic sugarcane leaf tissues in liquid nitrogen, and the frozen leaf powder was melted with a $6 \mathrm{~mL}$ extraction buffer containing $25 \mathrm{mM}$ Tris- $\mathrm{HCl}$ (pH 7.5), 1 mM EDTA, 0.01\% PMSF, 10\% polyvinylpolypyrrolidone (PVP), and $10 \mathrm{mM}$ 2-mercaptoethanol, and centrifuged at $12,000 \mathrm{rpm}$ for $10 \mathrm{~min}$ at $4{ }^{\circ} \mathrm{C}$. The supernatant containing soluble protein was stored at $-80^{\circ} \mathrm{C}$, and the pellet debris containing insoluble protein was washed with the extraction buffer once. The insoluble proteins were solubilized with a buffer containing $50 \mathrm{mM}$ Tris- $\mathrm{HCl}$ (pH 8.5), $1 \mathrm{mM}$ EDTA, 2\% SDS, and 30\% sucrose. The soluble and insolubilize proteins were separated with SDS-PAGE and subjected to western blot analysis using the raised antiserum.

\subsection{Indirect ELISA}

Approximately one gram of the tissue of healthy and symptomatic sugarcane leaves was ground in liquid nitrogen, and the protein was extracted by continues grinding in three times extraction buffer containing $50 \mathrm{mM}$ Mops- $\mathrm{NaOH}$ (pH 7.5), $10 \mathrm{mM} \mathrm{MgCl} 2,1 \mathrm{mM}$ EDTA, and $2 \%$ PVP at $4{ }^{\circ} \mathrm{C}$. The leaf extracts were centrifuged at $8000 \mathrm{rpm} 4{ }^{\circ} \mathrm{C}$ for $10 \mathrm{~min}$, and the supernatant was used for ELISA. The supernatant $(100 \mu \mathrm{L})$ was loaded into immunoplate wells and coated by an additional $100 \mu \mathrm{L}$ of coating buffer ( $\left.15 \mathrm{mM} \mathrm{Na}_{2} \mathrm{CO}_{3}, 35 \mathrm{NaHCO}_{3}, 2 \% \mathrm{PVP}, \mathrm{pH} 9.6\right)$, and then incubated at $4{ }^{\circ} \mathrm{C}$ overnight. The plate wells were washed tree times with TBS-T (tris-buffered saline plus $0.05 \%$ tween-20). The plate was blocked by addition $100 \mu \mathrm{L}$ of the blocking solution TBS-T, containing $1 \%$ skim milk and $0.5 \%$ BSA, incubated at room temperature for an hour, and then washed with TBS-T once. Amount of $100 \mu \mathrm{L}$ of diluted polyclonal antibody against recombinant coat protein with the blocking solution (1:1000) was added to the plate and incubated at room temperature for an hour. After washing the plate five times with TBS-T, $100 \mu$ L goat anti-rabbit IgG-AP conjugate (Sigma-Aldrich, St. Louis, MO, USA) at a dilution of 1:3000 in conjugate buffer was added and the plate was incubated at room temperature for an hour. The plate was further washed three times with TBS-T and then $100 \mu \mathrm{L}$ p-nitrophenyl phosphate (PNP) substrate $(0.6 \mathrm{mg} / \mathrm{mL}$ PNP 9.7\% in diethanolamine buffer, $\mathrm{pH} 9.6)$ was added. After an hour of incubation at room temperature, the absorbance was measured at A405 nm. For analyzing the ELISA results, the S/H ratio (sample A405/TBS-T buffer A405) was calculated. A reaction was considered positive if the A405 of sample was 1.75 greater than the A405 of the TBS-T buffer.

The sensitivity of the polyclonal antiserum against the recombinant coat protein was compared with a DAS-ELISA test using reagent set for sugarcane mosaic virus (Agdia, Inc., Elkhart, IN, USA). To conduct an analysis using the ELISA reagent set, approximately one gram of healthy and symptomatic sugarcane leaves was ground in liquid nitrogen, and the pulverized leaves powder was homogenized with three times volume of the sample buffer 1 (SB1) provided by the ELISA reagent set. After centrifugation, the supernatant was used for DAS-ELISA analysis according to the manufacturer's instructions (Agdia, Inc., Elkhart, IN, USA).

\section{Results}

\subsection{Cloning and Sequencing of SCMVCp-cDNA from Sugarcane Leaves}

To obtain a cDNA for the coat protein of SCMV, RT-PCR was conducted using an F1-R1 primer pair, which was designated from conserved region among various CDNA for the coat protein of SCMV.

Total RNA extracted from the symptomatic sugarcane leaf was used as a template for the RT-PCR reaction. As expected, a single cDNA band with a molecular size of around $1.0 \mathrm{~kb}$ was observed in gel electrophoresis separation. Thus, the cDNA fragment was then cloned into a pJET1.2 plasmid vector and transformed into E. coli XL10-Gold. Colony PCR analysis of the transformant confirmed the insertion of cDNA size of $1.0 \mathrm{~kb}$ in the plasmid vector. The sequence analysis revealed that the cDNA contained 998 nucleotides, and the sequence alignment at deduced amino acid level has a high homology (91\%) to the cDNAs for the coat protein of SCMV from Australia (GenBank: AJ278405.1), Argentine (GenBank: JX237868.1) and China (GenBank: AY590778.1) (Figure 1). The result showed that 
a full-length cDNA for a coat protein of SCMV was successfully cloned and named as SCMVCp-cDNA isolate PS881-Jember.

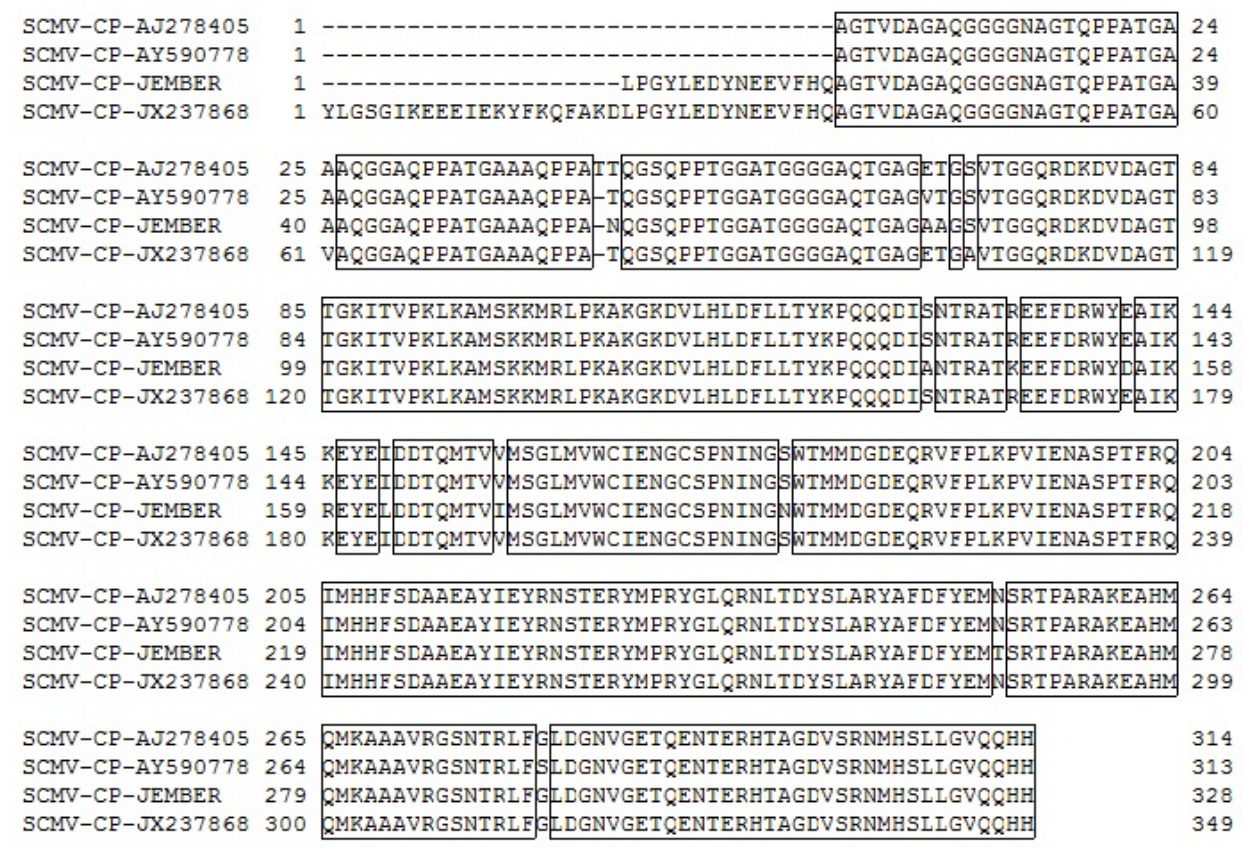

Figure 1. Multiple alignment at amino acid sequences of the SCMV coat proteins isolates from Australia (AJ278405.1), Argentina (JX237868.1), and China (AY590778.1), with isolate from PS881-Jember. Identical amino acid residues with isolate of Jember are indicated by boxed sequences. The three amino acids of DAG at N-terminal were used as initial amino acids for the synthesis of the recombinant coat protein.

\subsection{Expression and Purification of the Recombinant SCMVCp Fusion Protein}

To synthesize the SCMVCp fusion protein, the SCMVCp-cDNA was inserted into the pET-28a plasmid with 924 nucleotides encoding for 308 amino acids, and then introduced into E. coli BL21. The insertion was confirmed by isolation of the plasmid from the transformant E. coli and double digesting the plasmid with BamHI and XhoI, resulting in 924 bp DNA band. A similar result of DNA size was observed in PCR analysis using a set of primers, F2 and R2 (data not shown). The nucleotides sequences determination showed that the $S C M V C p$-cDNA was properly inserted into the BamHI and XhoI sites of the pET-28a plasmid, as expected. The inserted SCMVCp-cDNA began with nucleotides encoding for DAG amino acids and fused with nucleotides of hexa-histidine (6-His) tag at the $\mathrm{N}$ terminal.

To examine the expression of the recombinant SCMVCp fusion protein, the transformant E. coli was cultured in $100 \mathrm{~mL}$ LB media and induced by IPTG $(0.5 \mathrm{mM})$. SDS-PAGE analysis showed that the expression of the recombinant SCMVCp fusion protein was found to be plentiful in the total extract and in the insoluble fraction of the pellet debris of $E$. coli, with a molecular size of around $44 \mathrm{kDa}$, but was not presented in the supernatant as a soluble protein fraction (Figure 2A). This result is consistent with the experiments previously reported that the recombinant virus coat protein was expressed in the insoluble protein fraction $[13,15]$. Interestingly, the expression of the recombinant SCMVCp protein was not dose-dependent on the inducer IPTG. The addition of IPTG, with increasing concentration, starting from $0,0.1,0.5$, to $1 \mathrm{mM}$, did not elevate the recombinant coat protein contents (Figure 2B). This result suggests that metabolisms of tryptone-peptone in the LB media produce lactose that may be structurally similar to IPTG with respect to the induction of protein synthesis [21,22]. 


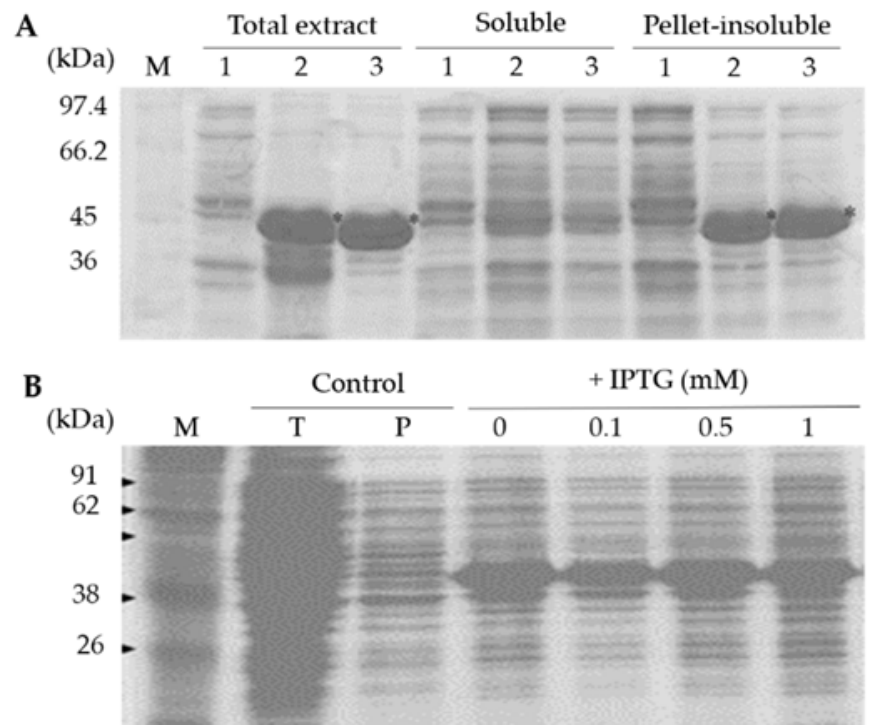

Figure 2. Electrophoresis separation of the SCMVCp recombinant protein expressed in E. coli (A) and the effect of IPTG concentration on SCMVCp levels (B); The E. coli strain BL 21 harboring a pET28a-SCMVC $p$ construct was grown in LB liquid media at $37^{\circ} \mathrm{C}$ on a $150 \mathrm{rpm}$ shaker and induced with $0.5 \mathrm{mM}$ of IPTG. The proteins were extracted by sonication, separated with SDS-PAGE (10\% acrylamide), and stained with Commassie brilliant blue; (A) lane 1: protein extracted from the E. coli control plasmid only and lane 2-3: protein extracted from the E. coli pET28a plasmid inserted with SCMVCp-cDNA; (B) Control; total (T) and insoluble proteins (P) from the E. coli control without the insert, and + the IPTG representing effect of IPTG addition at the indicated concentration. Lane $\mathrm{M}$ is the protein marker protein.

The recombinant SCMVCp fusion protein was extracted by solubilizing protein in the pellet debris using urea as a denaturant, and the purification was conducted using Ni-NTA resin, as described in Materials and Methods. Separation of the purified recombinant SCMVCp fusion protein with SDS-PAGE showed the presence of a major distinct protein band at around $44 \mathrm{kDa}$ that was eluted with $250 \mathrm{mM}$ imidazole (Figure 3 line 5). The presence of a little protein band, at the same molecular size after addition of washing buffer containing $20 \mathrm{mM}$ imidazole, suggested that the applied protein on the column chromatography exceeded the resin binding capacity (Figure 3 line 3-4).

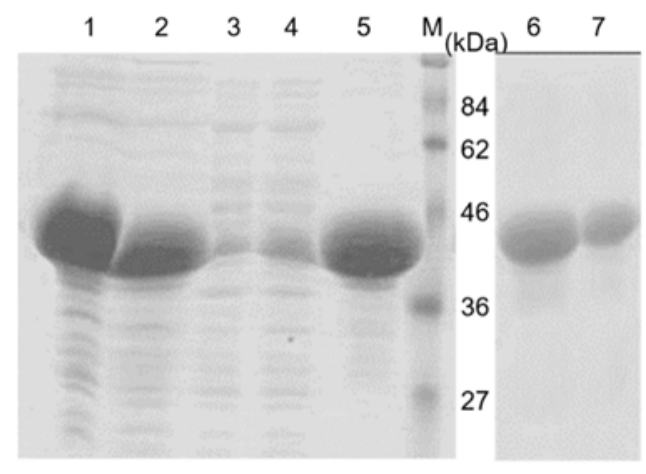

Figure 3. Separation of the purified recombinant SCMVCp protein using SDS-PAGE. The insoluble protein was extracted from the pellet, applied and fractionated into an affinity Ni-NTA resin. The fractioned protein was then separated by SDS-PAGE (10\% acrylamide) and stained with Coomasie Brilliant Blue. Lanes 1, 2, 3, 4, and 5 are the total-insoluble, re-loaded flow through, unbound, $20 \mathrm{mM}$-washed and $250 \mathrm{Mm}$-eluted imidazole protein fractions, respectively. Lane 6 and 7 show the protein after electroelution and dialyzed against PBS. $\mathrm{M}$ is a protein marker. 
The results imply that the recombinant fusion protein can be purified using a single step purification system of the Ni-NTA column. However, some unexpected minor protein bands were observed in the purified recombinant SCMVCp protein. To remove the unexpected protein, the purified recombinant coat protein was further separated by SDS-PAGE, and the targeted recombinant protein band was excised and then electro-eluted from the gel. SDS-PAGE analysis showed that the purity of the eluted recombinant SCMVCp protein increased its purity (Figure 3 line 6-7). Thus, the recombinant protein was dialyzed against PBS to remove SDS, allowing the protein to be used as antigen for developing the polyclonal antibody.

\subsection{Production of the Polyclonal Antibody}

Development of the polyclonal antibody was monitored by a double immunodiffusion of Ouchtherlony analysis. The developed antibody was revealed by precipitation that resulted from binding interaction between the recombinant protein and the antibody. The precipitation was formed in the antiserum after second booster injection and thereafter. The antiserum was then collected every week after the second, third, fourth, and fifth injections and named S2, S3, S4 and S5, respectively. To evaluate the sensitivity of the raised antiserum, western blot analysis was conducted using the antisera S5. The result showed that the antisera reacted well with the antigen recombinant SCMVCp protein with a molecular size of $44 \mathrm{kDa}$ at a very low protein concentration up to $10 \mathrm{ng}$ (Figure $4 \mathrm{~B}$ lane 3). However, when a pre-immune antiserum was used in western blot analysis, no corresponding protein bands were observed (Figure 4A). These results suggest that the polyclonal antibody against the SCMVCp protein successfully developed and had a high titer, making it suitable for the detection of SCMV infection in sugarcane.

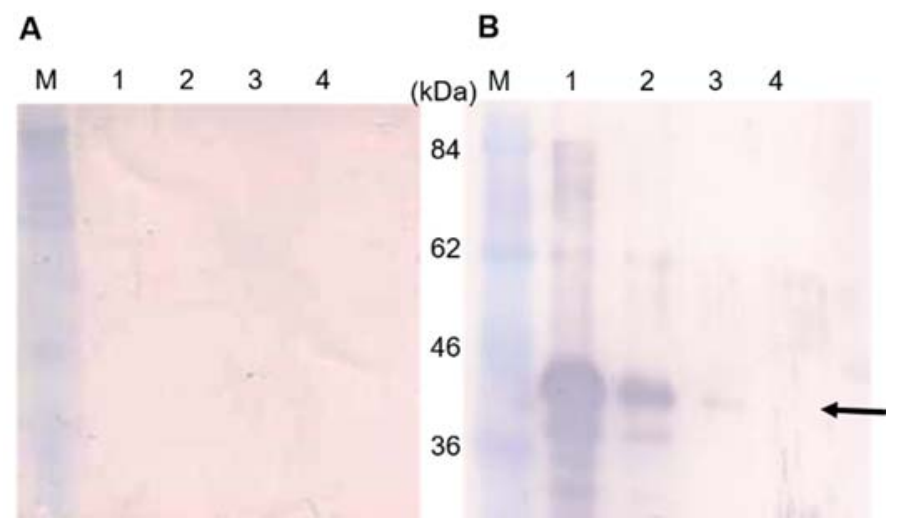

Figure 4. Western blot analysis of the recombinant SCMVCp protein. The purified recombinant proteins separated on SDS-PAGE and subjected to western blot analysis using pre-immune (A) and S5 serum (B). Lanes 1, 2, 3, and 4 are 1, 0.1, 0.01, and $0.001 \mu \mathrm{g}$ of the purified protein, respectively. $\mathrm{M}$ is a protein marker.

\subsection{Detection of SCMV Infection in Sugarcane Leaf}

The polyclonal antibody developed against the recombinant SCMVCp protein was evaluated by western blot analysis and ELISA for its specific reaction. Western blot analysis was conducted using crude proteins extracted from healthy and symptomatic sugarcane leaves. The healthy leaf showed no symptoms and appeared to stay green, but the three symptomatic leaves taken from different locations showed mosaic and yellowing (Figure 5A). The western blot analysis showed that the antiserum S5 clearly reacted with a single insoluble protein band extracted from symptomatic sugarcane leaf with a molecular size of $36.7 \mathrm{kDa}$ (Figure $5 \mathrm{~B}$ line $\mathrm{P}$ ). However, the corresponding protein band was not observed in the protein extracted from healthy sugarcane leaves. The results suggest that the coat protein of the SCMV has a molecular size of $36.7 \mathrm{kDa}$, and this size was comparable to the coat protein 
of papaya ringspot [23] and grapevine fanleaf viruses [24]. Furthermore, the molecular size of the SCMV coat protein was smaller compared to the recombinant fusion SCMVCp protein (Figure 5B line $\mathrm{R})$, due to the recombinant protein contained fusion hexa-histidine (6-His) and other additional amino acids at the first codon. Interestingly, when the crude extract was centrifuged at low speed (below $10,000 \mathrm{rpm}$ ), the antisera reacted with a soluble protein of the same molecular size extracted from symptomatic sugarcane leaves, but not from healthy leaves (Figure 5C). This result suggested that the SCMV virus particle was not precipitated at low-speed centrifugation, and western blot analysis using the antisera detected a SCMV coat protein in soluble protein fraction.
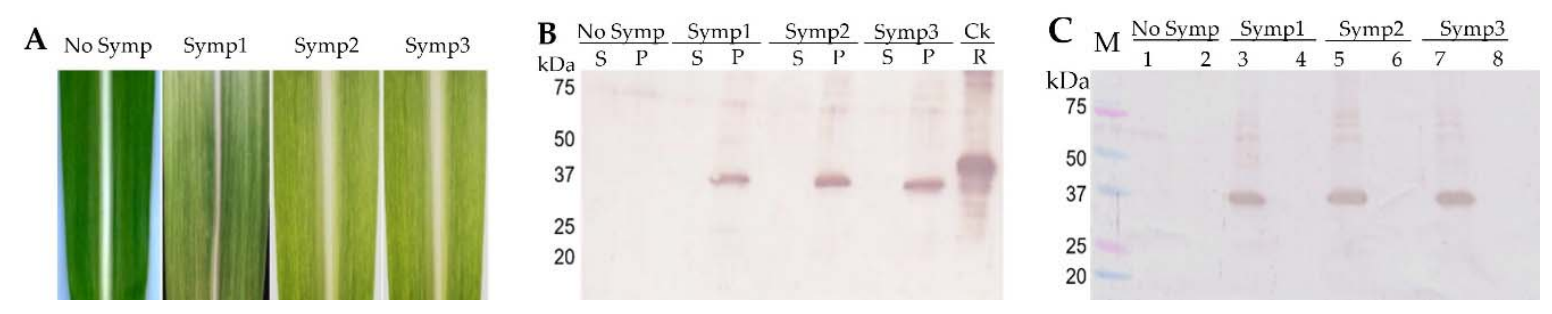

Figure 5. Detection of SCMV infection in sugarcane leaves using western blot analysis. (A) Photograph of healthy no-symptom and symptomatic sugarcane leaves; and $(\mathbf{B}, \mathbf{C})$ western blot analysis of the proteins extracted from the leaves sample using S5 serum; (B) the protein extract prepared by high speed centrifugation and (C) low speed centrifugation. No Symp and Symp represent no-symptom and symptomatic leaves. S, P, R (Ck), and M are soluble, insoluble, recombinant (control) protein, and marker proteins, respectively.

The sensitivity of the antisera was further tested with indirect-ELISA analysis using proteins extracted from healthy and symptomatic sugarcane leaves. The crude extract was separated from leaf debris at a low centrifugation at $8000 \mathrm{rpm} 4{ }^{\circ} \mathrm{C}$ for $10 \mathrm{~min}$ to maintain the virus particle in the soluble fraction. The S5 antiserum allowed for the detection of SCMV in the crude extracts of symptomatic sugarcane leaves, from undiluted up to 50 times dilution of crude extract. The dilution of the crude extracts gradually decreased the A405 nm, from 3.311 of undiluted to 1.538 of 50 times dilution (Table 1).

Table 1. Indirect-ELISA analysis for detection of the SCMV infection in sugarcane leaves. The ELISA analysis was conducted using the S5 antiserum and a series dilution of the protein samples extracted from healthy and symptomatic leaves.

\begin{tabular}{ccccc}
\hline Sugarcane Leaves Sample & Dilution & Mean Value of A405 & Response (Description) & S/H Ratio \\
\hline \multirow{3}{*}{ Symptomatic 1} & No dilution & 3.385 & infected & 2.557 \\
& 5 & 2.414 & infected & 1.979 \\
& 10 & 2.024 & infected & 2.222 \\
Symptomatic 2 & 50 & 1.937 & infected & 3.616 \\
& No dilution & 3.104 & infected & 2.345 \\
& 5 & 2.696 & infected & 2.210 \\
Symptomatic 3 & 10 & 1.605 & infected & 1.762 \\
& 50 & 1.503 & infected & 2.807 \\
\hline & No dilution & 3.444 & infected & 2.602 \\
No Symptom & 5 & 2.242 & infected & 1.838 \\
& 10 & 1.618 & infected & 1.776 \\
& 50 & 1.174 & infected & 2.191 \\
\hline & No dilution & 1.954 & not infected & 1.476 \\
& 5 & 1.796 & not infected & 1.472 \\
& 10 & 1.137 & not infected & 1.248 \\
\hline
\end{tabular}


Table 1. Cont.

\begin{tabular}{ccccc}
\hline Sugarcane Leaves Sample & Dilution & Mean Value of A405 & Response (Description) & S/H Ratio \\
\hline & No dilution & 1.324 & - & 1.000 \\
TBS-T buffer & 5 & 1.220 & - & 1.000 \\
& 10 & 0.911 & - & 1.000 \\
& 50 & 0.536 & - & 1.000 \\
\hline CP-SCMV (control) & No dilution & 3.482 & \\
\hline
\end{tabular}

Compared with symptomatic leaves, the A405 of the crude extract from healthy leaves and the TBS buffer were lower at all dilutions, ranging from 1.954 in the undiluted no-symptom leaf to 0.536 in the 50-times diluted TBS (Table 1). Calculation of the S/H ratio (sample A405/TBS buffer A405) resulted in more than twice in the all of undiluted and fifty times dilution of symptomatic leaves. However, in some dilution samples showed the ratio only close to twice. This result might be due to the high absorbance background in the TBS buffer. The reactions were considered positive-infected when the $S / H$ value was $\geq 2$ [13]. However, based on the calculation of $S / H$ ratio the symptomatic sugarcane leaves that showed the score higher than 1.75, the plant was considered to be infected. In addition, the healthy leaves were less than 1.75 , not considered to be infected. Thus, using both western blot and an indirect-ELISA test, the results suggest that the polyclonal antibody against the recombinant SCMVCp protein is useful for routine immunodiagnostic.

To compare the sensitivity of the polyclonal antibody, a separate experiment was conducted to detect SCMV infection in sugarcane leaves using an ELISA reagent kit. The results showed that the A405 of the symptomatic were slightly higher than the healthy leaves. (Table 2). The calculation of $\mathrm{S} / \mathrm{H}$ ratio (symptomatic/healthy A405) resulted in a score value of around 1.04-1.24, which is lower than the $\mathrm{S} / \mathrm{H}$ ratio mentioned in Table 1 . The results suggested that the polyclonal antibody against the recombinant SCMVCp protein has a higher sensitivity compared to the ELISA reagent kit.

Table 2. DAS-ELISA analysis for detection of the SCMV infection in sugarcane leaves. The ELISA analysis was conducted using an ELISA reagent set for SCMV (Agdia, Inc., Elkhart, IN, USA) and a three times diluted crude extract of sugarcane leaves.

\begin{tabular}{cccc}
\hline Sugarcane Leaves Sample & Mean Value of A405 & Response (Description) & S/H Ratio \\
\hline Symptomatic 1 & 0.09550 & Infected & 1.14 \\
Symptomatic 2 & 0.10413 & Infected & 1.24 \\
Symptomatic 3 & 0.08663 & Infected & 1.04 \\
Healthy & 0.08345 & - & - \\
\hline
\end{tabular}

\section{Discussion}

The SCMV is one among many viruses that infect and cause yield loss of sugarcane cultivated in East Java Indonesia [1]. Since the morphological symptom of SCMV is similar to symptoms caused by other diseases or the depletion of plant nutrition, the development of a serological method for the detection of SCMV infection is one of the most common methods to identify the disease. In addition, as a propagated vegetative plant, sugarcane is susceptible to contamination by virus through lateral buds during propagation. Therefore, it is valuable to establish a rapid, convenient, and reliable methods using the serological technique for viral detection. This method will facilitate the management for the prevention of the spread of the SCMV disease.

The alignment of nucleotides sequence showed that the SCMVCp-cDNA isolate PS881-Jember has a high similarity to the isolate from Argentine (GenBank: JX237868.1), China (GenBank: AY590778.1), and Australia (GenBank: AJ278405.1). In this study, the SCMVC $p$-cDNA was constructed in the plasmid with a His-tag fusion and expressed in E. coli BL21. The expression of the recombinant SCMVCp fusion protein was detected as an insoluble protein in the transformed E. coli BL21. Similarly, the insoluble 
expression of the recombinant coat protein has been reported for potato mop-top virus [10] and Pelargonium zonate spot virus [13]. Interestingly, the recombinant SCMVCp protein was strongly expressed and not induced by IPTG concentration (Figure 2B). The presence of lactose as well as galactose in complex LB media, even in minute amounts, might act as an inducer of the recombinant protein expression [21]. This leads to the fast and efficient production of the recombinant protein in the E. coli cell, which is subsequently purified using the affinity Ni-NTA resin. Since the His-tag fused in the recombinant protein was expected not to have immunogenic activity, the polyclonal antibody against the recombinant $\mathrm{CP}$ was successfully developed.

The polyclonal antibody developed against the recombinant coat protein virus has been widely employed in virus detection using western blot or ELISA methods. Our results clearly demonstrated that the polyclonal antibody against the recombinant SCMVCp fusion protein shows a high sensitivity and be able to detect the antigen as low as $10 \mathrm{ng}$ of the recombinant protein using western blot analysis (Figure 4B). The antibody is highly specific as it detects a single band of the SCMV coat protein extracted from the infected sugarcane leaves, and no visible protein band observed from leaves with no symptom (healthy) was detected. These results imply that the antibody is suitable for the detection of the SCMV virion using the ELISA method, since the technique requires an antibody that only matches with a single targeted protein and does not cross-react with other proteins. A sensitivity comparison has shown that the antibody is more sensitive to SCMV detection than the DAS-ELISA reagent kit for sugarcane mosaic virus (Agdia, Inc., Elkhart, IN, USA) (Table 2). Indirect ELISA analysis using the polyclonal antibody detected the SCMV in a 50 times diluted crude extract (Table 1), but the DAS-ELISA detected only three times diluted crude extract of symptomatic sugarcane leaves (Table 2). These results indicated differences in the specificity of the SCMV strain and the antibody sensitivity. The polyclonal antibody clearly detected the SCMV isolate PS881-Jember, but the ELISA reagent kit may work well with the SCMV strain from the USA and Australia. In addition, western blot analysis showed that the antibody detected a viral protein in a soluble fraction when the crude extract of infected leaves was centrifuged at below 10,000 rpm, but with ultra-centrifugation at 40,000 rpm, the protein was detected in an insoluble protein fraction. Thus, these results facilitate the easy detection of SCMV using ELISA method with low-speed centrifugation to maintain the virion in the soluble fraction.

The use of next-generation sequencing (NGS) for the identification and characterization of maize and sugarcane viruses has been reported $[25,26]$. It was claimed that the NGS method provides a powerful and rapid identifying potential diseases caused by virus, compared to the molecular and serological techniques. However, the NGS method needs sophisticated tools and bioinformatics expertise to process the NGS data [26]. Since the antibody against the targeted virus has been developed, virus detection by serological methods, such as western blot and ELISA, are widely accepted. In this study, the antibody prepared against recombinant the SCMVCp protein was demonstrated to be efficient for the detection of SCMV using both western blot and ELISA methods. The availability of this antibody facilitates the screening of sugarcane in sanitation programs and the development of SCMV-resistant sugarcane.

\section{Conclusions}

The polyclonal antibody agaisnt a recombinant coat protein of SCMV has been succesfully produced for immunodetection. The recombinant coat protein was generated by overexpression of $S C M V C p$-cDNA cloned from the symptomatic sugarcane leaves. The purified recombinant coat protein was then used to produce the polyclonal antibody in a New Zealand White rabbit. The polyclonal antibody has a high sensitivity and specificity for detection of SCMV isolate PS881-Jember using either Western blotting or indirect-ELISA methods. Thus, the polyclonal antibody provides an easy method to identify the causal agent of mosaic diseases and detect SCMV infection in sugarcane.

Author Contributions: B.S. and N.D. conceived and designed the experiments besides the contributed reagents/materials/analysis tools; N.D., N.N.A., K.M.P., and N.T.A. performed the experiments and analyzed the 
data; N.D., B.S., H.S.A., and W.D. conceived and designed the experiments; and B.S., H.S.A., and N.D. arranged and wrote the manuscript and conferred with all authors. All authors read and approved the final manuscript.

Acknowledgments: The research was supported by the Ministry of Research, Technology, and Higher Education through a research grant from the Islamic Development Bank (IDB) Project of The University of Jember and PBK/HIKOM of Airlangga University.

Conflicts of Interest: The authors declare no conflict of interest.

\section{References}

1. Addy, H.S.; Wahyudi, A.H.S.; Sholeh, A.; Anugrah, C.; Iriyanto, F.E.S.; Darmanto, W.; Sugiharto, B. Detection and response of sugarcane against the infection of Sugarcane mosaic virus (SCMV) in Indonesia. Agronomy 2017, 7, 50. [CrossRef]

2. Putra, L.K.; Kristini, A.N.; Achadian, E.M.; Damayanti, T.A. Sugarcane streak mosaic virus in Indonesia: Distribution, characterization, yield losses and management approaches. Sugar Tech 2014, 16, 392-399. [CrossRef]

3. Akbar, S.; Tahir, M.; Wang, M.-B.; Liu, Q. Expression analysis of hairpin RNA carrying Sugarcane mosaic virus (SCMV) derived sequences and transgenic resistance development in a model rice plant. BioMed Res. Int. 2017, 2017, 1-10. [CrossRef] [PubMed]

4. Haider, M.S.; Afghan, S.; Riaz, H.; Tahir, M.; Javed, M.A.; Rashid, N.; Iqbal, J. Identification of two Sugarcane mosaic virus (SCMV) variants from naturally infected sugarcane crop in Pakistan. Pak. J. Bot. 2011, 43, 1157-1162.

5. Fu, W.-L.; Sun, S.-R.; Fu, H.-Y.; Chen, R.-K.; Su, J.-W.; Gao, S.-J. A One-step Real-Time RT-PCR assay for the detection and quantitation of Sugarcane streak mosaic virus. BioMed. Res. Int. 2015, 2015, 1-9. [CrossRef]

6. Viswanathan, R.; Balamuralikrishnan, M. Impact of mosaic infection on growth and yield of sugarcane. Sugar Tech 2005, 7, 61-65. [CrossRef]

7. Hall, J.S.; Adams, B.; Parsons, T.J.; French, R.; Lane, L.C.; Jensen, S.G. Molecular cloning, sequencing, and phylogenetic relationship of a new potyvirus: Sugarcane streak mosaic virus, and a revaluation of the classification of the Potyviridae. Mol. Phyl. Evol. 1998, 10, 323-332. [CrossRef] [PubMed]

8. Kuntze, L.; Fuchs, E.; Grunztig, M.; Schulz, B.; Henning, U.; Hohmann, F.; Melchinger, A.E. Evaluation of maize inbred lines for resistance to Sugarcane mosaic virus (SCMV) and Maize dwarf mosaic virus (MDMV). Agronomie 1995, 15, 463-467. [CrossRef]

9. Zhu, M.; Chen, Y.; Ding, X.S.; Webb, S.L.; Zhou, T.; Nelson, R.S.; Fan, Z. Maize Elongin C interacts with the viral genome-linked protein, $\mathrm{VPg}$, of Sugarcane mosaic virus and facilitates virus infection. New Phytol. 2014, 203, 1291-1304. [CrossRef] [PubMed]

10. Cerovska, N.; Moravec, T.; Rosecka, P.; Dedic, P.; Filigarova, M. Production of polyclonal antibodies to a recombinant coat protein of Potato mop-top virus. J. Phytopathol. 2003, 151, 195-200. [CrossRef]

11. Hourani, H.; Abou-Jawdah, Y. Immunodiagnosis of Cucurbit yellow stunting disorder virus using polyclonal antibodies developed against recombinant coat protein. J. Plant Pathol. 2003, 85, 197-204. [CrossRef]

12. Hull, R. Matthews' Plant Virology, 4th ed.; Academic Press: San Diego, CA, USA, 2002; ISBN 9780080535999.

13. Gulati-Sakhuja, A.; Sears, J.L.; Nunez, A.; Sing, H.-Y.; Liu, Y. Production of polyclonal antibodies against Pelargonium zonate spot virus coat protein expressed in Escherichia coli and application for immunodiagnosis. J. Virol. Methods 2009, 160, 29-37. [CrossRef] [PubMed]

14. Khan, S.; Jan, A.T.; Aquil, B.; Haq, Q.M.R. Coat protein gene based characterization of Cucumber mosaic virus isolates infecting banana in India. J. Phytol. 2011, 3, 94-101.

15. Khatabi, B.; He, B.; Hajimorad, M.R. Diagnostic potential of polyclonal antibodies against bacterially expressed recombinant coat protein of Alfalfa mosaic virus. Plant Dis. 2012, 96, 1352-1357. [CrossRef]

16. Hartley, L.J. Cloning technologies for protein expression and purification. Curr. Opin. Biotechnol. 2006, 17, 359-366. [CrossRef] [PubMed]

17. Sorensen, H.P.; Mortense, K.K. Advanced genetic strategies for recombinant protein expression in Escherichia coli. J. Biotechnol. 2005, 115, 113-128. [CrossRef] [PubMed]

18. Esposito, D.; Chatterjee, D.K. Enhancement of soluble protein expression through the use of fusion tags. Curr. Opin. Biotechnol. 2006, 17, 353-358. [CrossRef] [PubMed] 
19. Sambrook, J.; Fritsch, E.F.; Maniatis, T. Molecular Cloning a Laboratory Manual, 2nd ed.; Cold Spring Harbor Laboratory Press: Cold Spring Harbor, NY, USA, 1989; ISBN 9780879693091.

20. Prabha, L.A.; Lopez-Moya, J.J.; Meihua, C.; Chintamani, D.A.; Thomas, P.P. Mutational analysis of the protein capsid N-terminal amino acids involved in potyvirus transmission by aphids. J. Gen. Virol. 1995, 76, 265-270. [CrossRef]

21. Studier, F.W. Stable expression clones and auto-induction for protein production in E. coli. Methods Mol. Biol. 2014, 1091, 17-32. [CrossRef] [PubMed]

22. Rosano, G.L.; Ceccarelli, E.A. Recombinant protein expression in Escherichia coli: Advances and challenges. Front. Microbiol. 2014, 5, 172. [CrossRef] [PubMed]

23. Sreenivasulu, M.; Sai, G.D.V.R. Development of recombinant coat protein antibody based IC-RT-PCR and comparison of its sensitivity with other immunoassays for the detection of Papaya ringspot virus isolates from India. Plant Pathol. J. 2010, 26, 25-31. [CrossRef]

24. Koolivand, D.; Bashir, N.S.; Behjatnia, S.A.; Joozani, R.J. Production of polyclonal antibody against Grapevine fanleaf virus movement protein expressed in Escherichia coli. Plant Pathol. J. 2016, 32, 452-459. [CrossRef] [PubMed]

25. Adams, I.P.; Miano, D.W.; Kinyua, Z.M.; Wangai, A.; Kimani, E.; Phiri, N.; Reeder, R.; Harju, V.; Glover, R.; Hany, U.; et al. Use of next-generation sequencing for the identification and characterization of Maize chlorotic mottle virus and Sugarcane mosaic virus causing maize lethal necrosis in Kenya. Plant Pathol. 2013, 62, 741-749. [CrossRef]

26. Li, Y.; Wang, H.; Nie, K.; Zhang, C.; Zhang, Y.; Wang, J.; Niu, P.; Ma, X. VIP: An integrated pipeline for metagenomics of virus identification and discovery. Sci. Rep. 2016, 6, 23774. [CrossRef] [PubMed]

(C) 2018 by the authors. Licensee MDPI, Basel, Switzerland. This article is an open access article distributed under the terms and conditions of the Creative Commons Attribution (CC BY) license (http:/ / creativecommons.org/licenses/by/4.0/). 